\title{
A morphological and molecular survey of Neoconidiobolus reveals a new species and two new combinations
}

\section{Yong Nie}

Anhui University of Technology

\section{Zi-Min Wang}

Anhui University of Technology

Xiao-Yong Liu

Chinese Academy of Sciences

Bo Huang ( $\sim$ bhuang@ahau.edu.cn )

Anhui Agricultural University

\section{Research Article}

Keywords: Ancylistaceae, Morphology, Taxonomy, Molecular Phylogeny

Posted Date: June 1st, 2021

DOl: https://doi.org/10.21203/rs.3.rs-186207/v1

License: (9) (1) This work is licensed under a Creative Commons Attribution 4.0 International License. Read Full License 


\section{Abstract}

The genus Neoconidiobolus was recently established to accommodate all members of the Conidiobolus subgenus Conidiobolus. Based on mitochondrial small subunit (mtSSU), nuclear large subunit (nucLSU) of rDNA and translation elongation factor 1-alpha (TEF1), this study further resolved the genus Neoconidiobolus into three clades, with three new taxa being added. They are N. kunyushanensis B. Huang \& Y. Nie, sp. nov., N. lamprauges (Drechsler) B. Huang \& Y. Nie, comb. nov., and N. nanodes (Drechsler) B. Huang \& Y. Nie, comb. nov. Meanwhile, a morphologial comparison among species in the three clades and a key to the species of the genus Neoconidiobolus are provided herein.

\section{Introduction}

Conidiobolus Brefeld (Ancylistaceae, Entomophthorales) was erected by Brefeld (1884). It is a large and worldwide distributed group containing 80 records in the Index Fungorum database

(http://www.indexfungorum.org/). Most members of Conidiobolus occur saprophytically in soil and on decaying leaves, and few have been noted as pathogens of insects, animals and humans (Vilela et al. 2010; Gryganskyi et al. 2012; Mendoza et al. 2014). During 1950s-1960s, almost all the 40 Conidiobolus species have been reported in the North America and South Asia (Drechsler 1952; Srinivasan and Thirumalachar 1961; Nie et al. 2020a). Till up now, more than 15 novel species were added in Conidiobolus (Bałazy et al. 1987; Waters and Callaghan 1989; Bałazy 1993; Tosi et al. 2004; Keller 2007; Waingankar et al. 2008; Huang et al. 2007; Nie et al. 2012, 2016, 2017, 2018, 2020b; Goffre et al. 2020), most being found from East Asia. According to the numerical taxonomy (King 1976a, b, 1977) and molecular phylogeny (Chen and Huang 2019; Nie et al. 2020a), 41 species are currently accepted in this genus.

Although some morphological and phylogenetic analyses proved Conidiobolus to be polyphyletic (Ben-Ze'ev and Kenneth 1982; Jensen et al. 1998; Callaghan et al. 2000; Gryganskyi et al. 2013; Spatafora et al. 2016; Nie et al. 2018), there is a long lack of comprehensive taxonomic studies on this genus. Recently, we proposed a taxonomic revision of the well-known genus Conidiobolus s.l. (Nie et al. 2020a). Combining molecular phylogeny with morphology resulted in a more natural classification: the traditional Conidiobolus s.l. was divided into four genera, Capillidium B. Huang \& Y. Nie 2020, Conidiobolus s.s. Brefeld 1884, Microconidiobolus B. Huang \& Y. Nie 2020, and Neoconidiobolus B. Huang \& Y. Nie 2020. Among these genera, the Neoconidiobolus accommodated all species in the traditional Conidiobolus subgenus Conidiobolus. It is mainly characterised by forcibly discharged and globose / pyriform / obovoid primary conidia, forcibly discharged and elongated secondary conidia, and two types of resting spores, zygospores and chlamydospores (King 1976a,b, 1977; Nie et al. 2020a). This taxonomic treatment was supported by the phylogenomic analyses of nuclear and mitochondrial genomes (Nie et al. 2019; Wang et al. 2020).

In all, the genus Neoconidiobolus currently includes 10 species: N. couchii, N. lachnodes, N. mirabilis, N. osmodes, N. pachyzygosporus, $N$. sinensis, $N$. stilbeus, $N$. stromoideus, $N$. thromboides, and $N$. vermicola (Chen and Huang 2018; Nie et al. 2012, 2016, 2018, 2020a). This study aims at characterizing a new species and two new combinations into the Neoconidiobolus on the basis of morphology. Their molecular phylogeny was also reconstructed by using the small subunit of the mitochondrial ribosomal DNA (mtSSU), the large subunit of nuclear ribosomal DNA (nucLSU), and the translation elongation factor 1-alpha (TEF1). Also, some new insights of Neoconidiobolus will be provided in this article. 


\section{Materials And Methods}

\section{Isolates and morphology}

Plant detritus was collected from Kunyu Mountain, Shandong Province, China. Isolations were carried out using the canopy plating approach (Drechsler 1952, King 1976a). A Petri dish incubated at $21^{\circ} \mathrm{C}$ with PDA (potato $200 \mathrm{~g}$, dextrose $20 \mathrm{~g}$, agar $20 \mathrm{~g}, \mathrm{H}_{2} \mathrm{O} 1000 \mathrm{ml}$ ) was inverted over the plant detritus. When entomophthoroid fungi were observed on the PDA canopy, they were transferred to a PDA plate. Morphological features were examined under an Olympus BX51 microscope (Olympus, Japan) with brigth-field and differential interference contrast (DIC) equipments. Photomicrographs were taken with an Olympus DP25 microscope-camera system (Olympus, Japan). Different fungal structures were measured and described with the method of King (1976a). The living culture was deposited in the Research Center for Entomogenous Fungi of Anhui Agricultural University, Anhui Province, China (RCEF), and duplicated in the China General Microbiological Culture Collection Center, Beijing, China (CGMCC). The dried cultures were deposited in the Herbarium Mycologicum Academiae Sinicae, Beijing, China (HMAS).

\section{DNA extraction, amplification and sequencing}

A portion of fungal mycelia was ground in liquid nitrogen with a pestle and mortar, and genomic DNA was extracted from the mycelia using the CTAB method (Watanabe et al. 2010)., The extracted DNA was stored in $100 \mu \mathrm{l}$ TE buffer (10 mM Tris-HCl, $1 \mathrm{mM}$ EDTA, $\mathrm{pH} 8.0$ ) at $-20^{\circ} \mathrm{C}$. Universal primer pairs used in the PCR amplification of nucLSU, mtSSU and TEF1 were LR0R (5'-ACC CGC TGA ACT TAA GC-3') / LR5 (5'-TCC TGA GGG AAA CTT CG-3') (Vilgalys and Hester 1990), mtSSU1 (5'-GCW GCA GTG RGG AAT NTT GGR CAA T-3') / mtSSU2R (5'-GTR GAC TAM TSR GGT ATC TAA TC-3') (Zoller et al. 1999), and EF983 (5'-GCY CCY GGH CAY CGT GAY TTY AT-3') / EF1aZ-1R (5'-ACA TCW CCG ACA CCC TTG ATC TTG - 3') (Nie et al. 2012), respectively. PCR reactions were performed according to Nie et al. (2020): denaturation at $95^{\circ} \mathrm{C}$ for $5 \mathrm{~min} ; 34$ cycles of denaturation at $94^{\circ} \mathrm{C}$ for $1 \mathrm{~min}$ plus $55 / 54 / 57^{\circ} \mathrm{C}$ (nucLSU / mtSSU / TEF1) for 2 min plus $72^{\circ} \mathrm{C}$ for $2 \mathrm{~min}$, and a final extra extension at $72{ }^{\circ} \mathrm{C}$ for $10 \mathrm{~min}$. The PCR products were sequenced with respective primers by Shanghai Genecore Biotechnologies Company (Shanghai, China). Sequences were assembled with BioEdit (Hall 1999). The obtained sequences were deposited in GenBank under the accession numbers MN061286 (nucLSU), MN061289 (mtSSU) and MN061483 (TEF1).

\section{Phylogenetic analyses}

Other nucLSU, TEF1 and mtSSU sequences of Neoconidiobolus spp. were downloaded from GeneBank for phylogenetic reconstruction. Seven species of Conidiobolus s.l. were chosen as outgroups (Table 1). The nucLSU, TEF1 and mtSSU sequences were locally aligned with BioEdit (Hall 1999) and concatenated with SequenceMatrix (Vaidya et al. 2011). Maximum Parsimony (MP) analyses were conducted with PAUP* 4.0b10 (Swofford 2002) using 1000 heuristic search replicates. The best models for the Maximum Likelihood (ML) and Bayesian Inference $(\mathrm{BI})$ analyses were selected with Akaike Information Criterion (AIC) by using jModelTest 2.1.7 (Guindon and Gascuel 2003; Darriba et al. 2012). ML tree was constructed using RAxML 8.1.17 with 1000 bootstrap replicates (Stamatakis 2014). The BI tree was constructed using MrBayes 3.2.2 (Ronquist and Huelsenbeck 2003). Markov Chain Monte Carlo (MCMC) chains ran until the convergences met and the standard deviation fell below 0.01. Phylogenetic trees were modified in FigTree 1.4 (Rambaut 2012). Sequence alignment and phylogenetic tree were deposited at TreeBase (submission ID S27217). 
Table 1

The taxa used in phylogenetic analyses.

\begin{tabular}{|c|c|c|c|c|c|}
\hline \multirow[t]{2}{*}{ Species } & \multirow[t]{2}{*}{ Strains* } & \multicolumn{3}{|c|}{ GenBank accession numbers } & \multirow[t]{2}{*}{ References } \\
\hline & & nucLSU & TEF1 & mtSSU & \\
\hline Capillidium adiaeretum & CGMCC 3.15888 & MN061284 & MN061481 & MN061287 & Nie et al. 2020 \\
\hline Ca. Iobatum & ATCC $18153(T)$ & JF816218 & JF816233 & MK301187 & $\begin{array}{l}\text { Nie et al. 2012, } \\
2020\end{array}$ \\
\hline Ca. rhysosporum & ATCC $12588(T)$ & JN131540 & JN131546 & MK301195 & $\begin{array}{l}\text { Nie et al. 2016, } \\
2020\end{array}$ \\
\hline Conidiobolus coronatus & NRRL 28638 & AY546691 & DQ275337 & DQ364224 & $\begin{array}{l}\text { Lutzoni et al. } \\
2004\end{array}$ \\
\hline Co. lamprauges & CBS 461.97 & MH874268 & - & - & Vu et al. 2019 \\
\hline Co. lamprauges & CBS 728.97 & MH874275 & - & - & Vu et al. 2019 \\
\hline Co. nanodes & CBS $154.56(\mathrm{~T})$ & MH869096 & - & - & Vu et al. 2019 \\
\hline Co. polytocus & ATCC $12244(T)$ & JF816213 & JF816227 & MK301194 & $\begin{array}{l}\text { Nie et al. 2012, } \\
2020\end{array}$ \\
\hline $\begin{array}{l}\text { Microconidiobolus } \\
\text { nodosus }\end{array}$ & ATCC $16577(T)$ & JF816217 & JF816235 & MK333388 & $\begin{array}{l}\text { Nie et al. 2012, } \\
2020\end{array}$ \\
\hline M. terrestris & ATCC $16198(T)$ & KX752050 & KY402208 & MK301199 & $\begin{array}{l}\text { Nie et al. 2016, } \\
2020\end{array}$ \\
\hline $\begin{array}{l}\text { Neoconidiobolus } \\
\text { antarcticus }\end{array}$ & ARSEF $6913(T)$ & DQ364207 & - & DQ364227 & $\begin{array}{l}\text { Nie et al. 2018, } \\
2020\end{array}$ \\
\hline N. couchii & ATCC $18152(T)$ & JN131538 & JN131544 & MK301179 & $\begin{array}{l}\text { Nie et al. 2016, } \\
2020\end{array}$ \\
\hline N. kunyushanensis & $\begin{array}{l}\text { CGMCC } 3.15890 \\
\text { (T) }\end{array}$ & MN061286 & MN061483 & MN061289 & This article \\
\hline N. lachnodes & ARSEF 700 & KC788408 & - & - & $\begin{array}{l}\text { Nie et al. 2018, } \\
2020\end{array}$ \\
\hline N. mirabilis & $\begin{array}{l}\text { CGMCC } 3.17763 \\
\text { (T) }\end{array}$ & $\mathrm{MH} 282852$ & $\mathrm{MH} 282853$ & MK333389 & $\begin{array}{l}\text { Nie et al. 2018, } \\
2020\end{array}$ \\
\hline N. osmodes & ARSEF 79 & EF392371 & - & DQ364219 & $\begin{array}{l}\text { Chen and } \\
\text { Huang } 2018\end{array}$ \\
\hline N. osmodes & RCEF 4447 & JN131539 & JN131545 & MK333392 & $\begin{array}{l}\text { Nie et al. 2016, } \\
2020\end{array}$ \\
\hline N. pachyzygosporus & $\begin{array}{l}\text { CGMCC } 3.17764 \\
(T)\end{array}$ & KP218521 & KP218524 & MK333390 & $\begin{array}{l}\text { Nie et al. 2018, } \\
2020\end{array}$ \\
\hline
\end{tabular}

*ARSEF, ARS Entomopathogenic Fungus Collection (Ithaca, U.S.A.). ATCC, American Type Culture Collection (Manassas, U.S.A). CBS, Westerdijk Fungal Biodiversity Institute (Utrecht, The Netherlands). CGMCC, China General Microbiological Culture Collection Center (Beijing, China). FSU, Jena Microbial Resource Collection (Friedrich-Schiller-University of Jena, Germany). NRRL, ARS Culture Collection (Peoria, U.S.A). RCEF, Research Center for Entomogenous Fungi (Hefei, China). T = ex-type. 


\begin{tabular}{|c|c|c|c|c|c|}
\hline \multirow[t]{2}{*}{ Species } & \multirow[t]{2}{*}{ Strains* } & \multicolumn{3}{|c|}{ GenBank accession numbers } & \multirow[t]{2}{*}{ References } \\
\hline & & nucLSU & TEF1 & $\mathrm{mtSSU}$ & \\
\hline N. sinensis & RCEF 4952 (T) & JF816224 & JF816238 & MK301196 & $\begin{array}{l}\text { Nie et al. 2012, } \\
2020\end{array}$ \\
\hline N. stilbeus & RCEF $5584(T)$ & KP218522 & KP218525 & MK301197 & $\begin{array}{l}\text { Nie et al. 2016, } \\
2020\end{array}$ \\
\hline N. stromoideus & ATCC $15430(T)$ & JF816219 & JF816229 & MK301198 & $\begin{array}{l}\text { Nie et al. 2012, } \\
2020\end{array}$ \\
\hline N. thromboides & ATCC $12587(\mathrm{~T})$ & JF816214 & JF816230 & MK301200 & $\begin{array}{l}\text { Nie et al. 2012, } \\
2020\end{array}$ \\
\hline N. thromboides & FSU 785 & JX242597 & - & $J X 242637$ & $\begin{array}{l}\text { Gryganskyi et } \\
\text { al. } 2012\end{array}$ \\
\hline N. thromboides & RCEF 4492 & JF816223 & JF816236 & MK333393 & $\begin{array}{l}\text { Nie et al. 2012, } \\
2020\end{array}$ \\
\hline \multicolumn{6}{|c|}{$\begin{array}{l}\text { *ARSEF, ARS Entomopathogenic Fungus Collection (Ithaca, U.S.A.). ATCC, American Type Culture Collection } \\
\text { (Manassas, U.S.A). CBS, Westerdijk Fungal Biodiversity Institute (Utrecht, The Netherlands). CGMCC, China } \\
\text { General Microbiological Culture Collection Center (Beijing, China). FSU, Jena Microbial Resource Collection } \\
\text { (Friedrich-Schiller-University of Jena, Germany). NRRL, ARS Culture Collection (Peoria, U.S.A). RCEF, Research } \\
\text { Center for Entomogenous Fungi (Hefei, China). T = ex-type. }\end{array}$} \\
\hline
\end{tabular}

\section{Results}

\section{Phylogeny in Neoconidiobolus}

The combined nucLSU + TEF1 + mtSSU datasets consisted of 24 taxa and 1880 characters. Except 931 constant characters, 787 characters were parsimony-informative and 162 parsimony-uninformative. The characters 1$1025,1026-1526$ and $1527-1880$ were partitined to nucLSU, TEF1 and mtSSU, respectively. A parsimonious tree was generated with a length of $2913(\mathrm{Cl}=0.5287, \mathrm{HI}=0.4713, \mathrm{RI}=0.6132, \mathrm{RC}=0.3242)$. Best model estimated for the matrix was GTR $+I+G$. For the ML analysis, the final ML Optimization Likelihood is - 14492.684374. For the $\mathrm{Bl}$ analysis, Markov chains ran from random starting trees for 0.5 million generations and trees were sampled every 100th generations. When convergent, and the average standard deviation of split frequencies was 0.002707. ML, MP and BI analyses of the combined dataset resulted in similar topologies and the ML tree was presented with MP/ML/BI robustness values along branches. The members of Neoconidiobolus (82/98/1.00) were grouped into three clades (FIG. 1). Clade I included five species $N$. thromboides, N. mirabilis, N. sinensis, $N$. stromoideus and $N$. stilbeus (96/99/1.00) Clade II included four species $N$. lampauges comb. nov., $N$. kunyushanensis sp. nov., N. nanodes comb. nov. and $N$. lachnodes (77/73/0.98). Clade III included four species N. antarcticus, N. osmodes, N. couchii and N. pachyzygosporus (100/100/1.00).

\section{Taxonomy}

New species

Neoconidiobolus kunyushanensis B. Huang \& Y. Nie, sp. nov., Fig. 2 
MycoBank no. MB831600

Etymology. kunyushanensis (Lat.), referring to the geographical location where the fungus was isolated.

Known distribution. Shandong Province, China.

Specimens examined. China, Shandong Province, Yantai City, Kunyu Mountain, $37^{\circ} 26^{\prime} \mathrm{N}, 121^{\circ} 74^{\prime} \mathrm{E}$, from plant detritus, 20 Mar 2009, C.F. Wang, HMAS 248357, holotype, culture ex-holotype CGMCC 3.15890 (= RCEF 4584). GenBank: nucLSU = MN061286; TEF1 = MN061483; mtSSU = MN061289).

Description. Colonies white, reaching ca 25-30 mm diameter on PDA for $3 \mathrm{~d}$ at $21^{\circ} \mathrm{C}$. Mycelia colorless, 3.5$9.0 \mu \mathrm{m}$ wide, usually branched at the colony edge. Primary conidiophores colorless, often widening upward near the tip, mostly unbranched and producing a single conidium, 62.0-121.0 × 7.0-12.0 $\mu \mathrm{m}$, in some instances 2 primary conidiophores without widening arising from hyphal bodies at the same point. Primary conidia forcibly discharged, colorless, globose to subglobose, 13.0-17.0 $\mu \mathrm{m}$ wide and 15.0-21.0 $\mu \mathrm{m}$ long, with a basal papilla 4.0-8.0 $\mu \mathrm{m}$ wide and 1.0-4.0 $\mu \mathrm{m}$ long. Secondary conidia arising from the primary ones with a similar shape and a smaller size. Zygospores formed between segments of separate hyphae, smooth, mostly globose, sometimes ellipsoidal, 12.0-25.0 $\mu \mathrm{m}$ in diameter with a wall 1.0-2.8 $\mu \mathrm{m}$ thick.

Notes. Neoconidiobolus kunyushanensis sp. nov. is grouped with other three Neoconidiobolus species, i.e. $N$. lampauges comb. nov., N. nanodes comb. nov. and N. lachnodes (MP / ML / BI = 77 / 73 / 0.98; Clade II in Fig. 1). It is phylogenetically closely related to $N$. lamprauges (MP / ML / BI = 87 / 91 / 1.00; Fig. 1) and morphologically most allied to $N$. lamprauges (Table 2). This new species differs from $N$. lamprauges by two primary conidiophores without widening upward near the tip arising from hyphal body at the same point, larger zyogspores, and branched mycelia at the colony edge. In addition, the conidia usually filled with a large mass of conglutinated protoplasmic lumps in N. kunyushanensis, but with densely granular protoplasm in N. lamprauges (Drechsler 1953). 
Table 2

Morphological comparison of Neoconidiobolus species in three Clades in Fig. 1.

\begin{tabular}{|c|c|c|c|c|c|c|c|}
\hline Clades & Species & $\begin{array}{l}\text { Growth } \\
\text { rate } \\
(\mathrm{mm} / \mathrm{d}) \\
\text { at } 21^{\circ} \mathrm{C} \\
\text { on PDA }\end{array}$ & $\begin{array}{l}\text { Diameter } \\
\text { of } \\
\text { mycelia } \\
(\mu \mathrm{m})\end{array}$ & $\begin{array}{l}\text { Primary } \\
\text { conidiophores } \\
(\mu \mathrm{m})\end{array}$ & $\begin{array}{l}\text { Primary } \\
\text { conidia } \\
(\mu \mathrm{m})\end{array}$ & $\begin{array}{l}\text { Resting } \\
\text { spores } \\
\text { (jm) }\end{array}$ & References \\
\hline \multirow[t]{5}{*}{ Clade I } & N. mirabilis & $3.3-5.0$ & $6.0-12.0$ & $\begin{array}{l}40.0-145.0 \times \\
6.0-9.5\end{array}$ & $\begin{array}{l}20.5- \\
27.5 \times \\
16.5- \\
21.0\end{array}$ & $\begin{array}{l}13.5- \\
21.0 \times \\
1.5- \\
2.3\end{array}$ & Nie et al. 2018 \\
\hline & N. sinensis & 7.0 & $5.0-10.0$ & $\begin{array}{l}32.5-110.0 \times \\
10.0-15.0\end{array}$ & $\begin{array}{l}22.5- \\
32.5 \times \\
17.5- \\
25.0\end{array}$ & $\begin{array}{l}25.0- \\
31.0 \times \\
1.0- \\
2.0\end{array}$ & Nie et al. 2012 \\
\hline & N. stilbeus & $7.3-8.3$ & $5.0-10.0$ & $\begin{array}{l}68.0-133.0 \times \\
10.0-12.0\end{array}$ & $\begin{array}{l}21.0- \\
25.0 \times \\
17.0- \\
21.0\end{array}$ & $\begin{array}{l}15.0- \\
19.0 \times \\
1.0- \\
2.5\end{array}$ & Nie et al. 2016 \\
\hline & N. stromoideus & $\begin{array}{l}3.8- \\
10.0\end{array}$ & $7.0-9.0$ & $12.0-40.0$ & $\begin{array}{l}25.0- \\
33.0 \times \\
22.0- \\
26.0\end{array}$ & $\begin{array}{l}23.0- \\
32.0 \times \\
1.0- \\
2.0\end{array}$ & $\begin{array}{l}\text { Srinivasan } \\
\text { and } \\
\text { Thirumalachar } \\
1962\end{array}$ \\
\hline & N. thromboides & $\begin{array}{l}10.0- \\
15.0\end{array}$ & $3.0-10.5$ & $\begin{array}{l}35.0-150.0 \times \\
10.0-15.0\end{array}$ & $\begin{array}{l}24.0- \\
32.0 \times \\
19.0- \\
26.5\end{array}$ & $\begin{array}{l}17.5- \\
27.0 \times \\
2.0- \\
2.5\end{array}$ & $\begin{array}{l}\text { Drechsler } \\
1953\end{array}$ \\
\hline \multirow[t]{4}{*}{$\begin{array}{l}\text { Clade } \\
\text { II }\end{array}$} & N. lachnodes & $2.6-7.1$ & $2.0-8.0$ & $\begin{array}{l}15.0-40.0 \times \\
5.0-10.0\end{array}$ & $\begin{array}{l}10.0- \\
27.0 \times \\
9.0- \\
25.0\end{array}$ & $\begin{array}{l}11.0- \\
16.0\end{array}$ & $\begin{array}{l}\text { Drechsler } \\
1955 b\end{array}$ \\
\hline & N. lamprauges & $\begin{array}{l}\text { less } \\
\text { than } \\
5.0\end{array}$ & $\begin{array}{l}3.0-8.0 \\
(4.0- \\
7.0)\end{array}$ & $\begin{array}{l}25.0-100.0 \\
(25.0-50.0) \times \\
4.0-8.0(5.0- \\
15.0)\end{array}$ & $\begin{array}{l}15.0- \\
22.0 \times \\
12.5- \\
20.0\end{array}$ & $\begin{array}{l}12.0- \\
18.0 \times \\
1.3- \\
2.2\end{array}$ & $\begin{array}{l}\text { Drechsler } \\
1953\end{array}$ \\
\hline & $\begin{array}{l}N . \\
\text { kunyushanensis }\end{array}$ & $\begin{array}{l}8.3- \\
10.0\end{array}$ & $3.5-9.0$ & $\begin{array}{l}62.0-121.0 \times \\
7.0-12.0\end{array}$ & $\begin{array}{l}15.0- \\
21.0 \times \\
13.0- \\
17.0\end{array}$ & $\begin{array}{l}12.0- \\
25.0 \times \\
1.0- \\
2.8\end{array}$ & This article \\
\hline & N. nanodes & - & $2.0-7.0$ & $\begin{array}{l}10.0-25.0 \times \\
3.5-6.0\end{array}$ & $\begin{array}{l}10.0- \\
17.0 \times \\
8.0- \\
14.0\end{array}$ & $\begin{array}{l}7.0- \\
14.0 \times \\
0.8- \\
2.0\end{array}$ & $\begin{array}{l}\text { Drechsler } \\
1955 b\end{array}$ \\
\hline \multirow[t]{2}{*}{$\begin{array}{l}\text { Clade } \\
\text { III }\end{array}$} & N. couchii & 3.0 & $3.5-6.0$ & $\begin{array}{l}30.0-50.0 \times \\
4.0-7.0\end{array}$ & $\begin{array}{l}12.5- \\
27.0 \times \\
10.0- \\
16.0\end{array}$ & $\begin{array}{l}12.0- \\
16.0 \times \\
0.8- \\
1.2\end{array}$ & $\begin{array}{l}\text { Srinivasan } \\
\text { and } \\
\text { Thirumalachar } \\
1968\end{array}$ \\
\hline & N. osmodes & 7.5 & $4.0-12.0$ & $\begin{array}{l}30.0-60.0 \times \\
9.0-15.0\end{array}$ & $\begin{array}{l}25.0- \\
37.0 \times \\
22.0- \\
30.0\end{array}$ & $\begin{array}{l}13.0- \\
37.0 \times \\
2.0- \\
6.5\end{array}$ & $\begin{array}{l}\text { Drechsler } \\
1954\end{array}$ \\
\hline
\end{tabular}




\begin{tabular}{|c|c|c|c|c|c|c|c|}
\hline Clades & Species & $\begin{array}{l}\text { Growth } \\
\text { rate } \\
(\mathrm{mm} / \mathrm{d}) \\
\text { at } 21^{\circ} \mathrm{C} \\
\text { on PDA }\end{array}$ & $\begin{array}{l}\text { Diameter } \\
\text { of } \\
\text { mycelia } \\
(\mu \mathrm{m})\end{array}$ & $\begin{array}{l}\text { Primary } \\
\text { conidiophores } \\
(\mu \mathrm{m})\end{array}$ & $\begin{array}{l}\text { Primary } \\
\text { conidia } \\
(\mu \mathrm{m})\end{array}$ & $\begin{array}{l}\text { Resting } \\
\text { spores } \\
(\mu \mathrm{m})\end{array}$ & References \\
\hline & $\begin{array}{l}N . \\
\text { pachyzygosporus }\end{array}$ & 12.0 & $3.0-14.0$ & $\begin{array}{l}34.0-156.0 \times \\
6.0-12.0\end{array}$ & $\begin{array}{l}15.5- \\
23.0 \times \\
11.0- \\
18.0\end{array}$ & $\begin{array}{l}15.0- \\
25.0 \times \\
2.0- \\
3.2\end{array}$ & Nie et al. 2018 \\
\hline
\end{tabular}

\section{New combinations}

Neoconidiobolus lamprauges (Drechsler) B. Huang \& Y. Nie, comb. nov.

MycoBank no. MB837759

Conidiobolus lamprauges Drechsler, J. Wash. Acad. Sci. 43: 35 (1953). Basionym.

Description. Refer to Drechsler (1953).

Notes. The ex-type living culture is ATCC 12592 (United States, Virginia, 22 January 1952, Drechsler). According to the original morphological description and illustration (Drechsler 1953), Conidiobolus lamprauges should be allied to the Neoconidiobolus or Microconidiobolus lineages. In this phylogenetic analysis, two authentic strains CBS 154.56 and CBS 728.97 of the species C. lamprauges (Vu et al. 2019) were located in the Clade II of the Neoconidiobolus lineage, and therefore it was reclassified herein as a new combination in the genus Neoconidiobolus.

Neoconidiobolus nanodes (Drechsler) B. Huang \& Y. Nie, comb. nov.

MycoBank no. MB837760

Conidiobolus nanodes Drechsler, Am. J. Bot. 42: 439 (1955). Basionym.

Description. Refer to Drechsler (1955b).

Notes. The ex-type living culture is ATCC 12585 (United States, New Jersey, 25 February 1954, Drechsler). King (1977) synonymized Conidiobolus nanodes with C. lamprauges on the basis of their similar size and components of primary conidia. However, the primary conidia and zygospores of $C$. nanodes are smaller than $C$. lamprauges (Table 2); they were grouped into two distinct branches in the Neoconidiobolus phylogram (Fig. 1). Consequently, C. nanodes recovered its specific status and be accepted as a new combination in the genus Neoconidiobolus.

\section{Discussion}

The 12 Neoconidiobolus species in the three Clades within Neoconidiobolus (Fig. 1) were morphologically compared (Table 2). In general, we found species in Clade II share smaller primary conidia than members in Clade I (except N. stilbeus) and Clade III (except $N$. pachyzygosporus). This morphological characteristic might separate Clade II as a monophyletic taxa from Neoconidiobolus in the future upon the availability of more types. 
Remarkably, the Microconidiobolus, an allied genus of Neoconidiobolus, is also characterized by small primary conidia resembling those of the Clade II within the Neoconidiobolus in size and shape. Besides, Capillidium pumilum, a species of another allied genus, also produces small primary conidia $(7.3-14.0 \times 9.0-18.0 \mu \mathrm{m}$; Drechsler 1955a). These exceptions indicated that the relationshipa within the Conidiobolus s.l. need further studies, including more ex-type materials, new phenotypes such as the maximum growth temperature and the nuclear number in primary conidia, and phylogenomics fore a insightful understanding.

Besides the species recognized in this article, three other species should also be treated in Neoconidiobolus morphologically. They are Conidiobolus eurymitus Drechsler producing elongate secondary conidia and allied to N. couchii (Drechsler 1965; Srinivasan MC and Thirumalachar MJ 1968), C. multivagus Drechsler in which resting spores has not been observed (Drechsler 1960), and C. thermophilus Waingankar, Singh \& Srinivasan which is a thermophilic fungus. Unfortunately, there was no molecular evidence to support the morphological affinity, so we classified them into Conidiobolus s.l. herein and their taxonomic status should be clarified in the future study. Actually, two more issues make it difficult: 1) The type species $C$. utriculosus Brefeld and some other ex-types are missing; 2) As environmental species, it is often not possible to obtain multiple strains per species except a few common species.

We noted that recent phylogenetic analyses showed that $N$. antarcticus and $N$. osmodes did not group together (Goffre et al. 2020). However, our previous phylogeny showed that these two species grouped in one clade with a robust support (Chen and Huang 2018; Nie et al. 2016, 2017, 2018, 2020a). Also, the phylogenetic tree in this article supports $N$. antarcticus synonymized with $N$. osmodes. In addition, molecular data of $N$. lachnodes and $N$. osmodes were not type-derived sequences, but the morphological characteristic confirmed their taxonomic placement in Neoconidiobolus.

Until now, 13 species have been accepted in the genus Neoconidiobolus based on the combined morphology and phylogeny: $N$. couchii, $N$. kunyushanensis, $N$. lachnodes, $N$. lamprauges, $N$. mirabilis, $N$. nanodes, $N$. osmodes, $N$. pachyzygosporus, $N$. sinensis, $N$. stilbeus, $N$. stormoideus, $N$. thromboides and $N$. vermicola. More than half are distributed in China, including two pandemic species ( $N$. osmodes and $N$. thromboides) and five China-endemic species (N. kunyushanensis, N. mirabilis, N. pachyzygosporus, N. sinensis and N. stilbeus) (Chen and Huang 2018, Nie et al. 2012, 2016, 2018, 2020a).

\section{Key to the species of Neoconidiobolus}

1. Forming mycelial strand with 2-6 aerial phototropic hyphae $N$ stilbeus

$1 '$. Not forming mycelial strand 2

2. Primary conidiophores produced from cushion mycelia.

3

2'. Primary conidiophores not produced from cushion mycelia.

4

3. Usually branched at edge mycelia, much shorter conidiophores $(12-40 \mu \mathrm{m})$ produced N. stromoideus 
3'. Rarely branched at edge mycelia, much longer conidiophores $(32.5-110 \mu \mathrm{m})$ produced $N$. sinensis

4. Sepcially forming zygospores among two to four adjacent hyphal segments. .$N$. mirabilis

4'. Forming zygospores among two adjacent hyphal segments. 5

5. Zygospores with a thick double wall, more than

$3.2 \mu \mathrm{m}$. 6

5'. Zygospores with a thin single wall, less than $3.0 \mu \mathrm{m}$. 7

6. Primary conidia larger, up to $37 \mu \mathrm{m}$ N. osmodes

6'. Primary conidia smaller, less than $23 \mu \mathrm{m}$. $N$. pachyzygosporus

7. Elongate secondary conidia produced..... N. couchii

7'. Elongate secondary conidia not produced.

8. Primary conidiophores in pairs arising from hyphal bodies N. kunyushanensis sp. nov.

8'. Primary conidiophore solely arising from hyphal bodies

9. Primary conidia larger, up to $32 \mu \mathrm{m}$ N. thromboides

9'. Primary conidia smaller, less than $27 \mu \mathrm{m}$ 10

10. Forming azygosporus. N. vermicola

10'. Not forming azygosporus. .11

11. Primary conidiophores longer, up to $130 \mu \mathrm{m}$ N. lamprauges comb. nov.

11 '. Primary conidiophores shorter, less than $40 \mu \mathrm{m}$

12. Primary conidia larger, up to $27 \mu \mathrm{m}$

N. lachnodes

12'. Primary conidia smaller, less than $17 \mu \mathrm{m}$

N. nanode comb.

nov.

\section{Declarations}


We thank Dr. Shuang-hui He (Beijing Forestry University) for improving the manuscript. Mrs. C.F. Wang and Dr. Deshui Yu (Anhui Agricultural University) are acknowledged for helping with specimen collection and molecular work.

\section{Funding}

This work was supported by National Natural Science Foundation of China $(30770008,31900008$, and 31970009).

\section{Conflicts of interest}

The authors declare that they have no conflict of interest.

\section{Ethical approval}

This article does not contain any studies with human participants or vertebrates performed by any of the authors.

\section{Authors' contributions}

Conceived and designed the experiments: BH. Performed the experiments: YN. Analyzed the data: YN, ZW. Wrote the paper: YN, XL. All authors read and approved the final manuscript.

\section{Data availability}

The datasets including the sequences on GenBank, the specimen data on MycoBank and the phylogenetic data on TreeBase will be available to any researcher wishing to use them for non-commercial purposes, without breaching participant confidentiality.

\section{References}

Bałazy S, Wiśniewski J, Kaczmarek S (1987). Some noteworthy fungi occurring on mites. Bulletin of the Polish Academy of Sciences, Biological Sciences 35:199-224.

Balazy S (1993). Entomophthorales. Flora of Poland (Flora Polska), Fungi (Mycota) 24:1-356. Polish Academy of Sciences, W. Szafer Institute of Botany, Kraków, Poland.

Ben-Ze'ev IS, Kenneth RG (1982). Features-criteria of taxonomic value in the Entomophthorales: I. A revision of the Batkoan classification. Mycotaxon 14:393-455.

Brefeld $\mathrm{O}$ (1884). Conidiobolus utriculosus und minor. Untersuchungen aus der Gesammtgebiete der Mykologie 6(2):35-78.

Callaghan AA, Waters SD, Manning RJ (2000). Alternative repetitional conidia in Conidiobolus adiaeretus: development and germination. Mycological Research 104: 1270-1275.

https://doi.org/10.1017/S0953756200003063

Chen MJ, Huang B (2018). Conidiobolus antarcticus, a synonym of C. osmodes. Mycotaxon 133(4):635-641. https://doi.org/10.5248/133.635. 
Darriba D, Taboada GL, Doallo R, Posada D (2012). jModelTest 2: more models, new heuristics and parallel computing. Nature Methods 9(8):772. https://doi.org/10.1038/nmeth.2109.

Drechsler C (1952). Widespread distribution of Delacroixia coronata and other saprophytic Entomophthoraceae in plant detritus. Science 115:575-576. https://doi.org/10.1126/science.115.2995.575.

Drechsler C (1953). Three new species of Conidiobolus isolated from leaf mold. Journal of the Washington Academy of Science 43(2):29-34.

Drechsler C (1954). Two species of Conidiobolus with minutely ridged zygospores. American Journal of Botany 41: 567-575. https://doi.org/10.1002/j.1537-2197.1954.tb14380.x.

Drechsler C (1955a). A small Conidiobolus with globose and with elongated secondary conidia. Journal of Washington Academy of Sciences 45(4):114-117.

Drechsler C (1955b). Three new species of Conidiobolus isolated from decaying plant detritus. American Journal of Botany 42(5):437-443. https://doi.org/10.1002/j.1537-2197.1955.tb11144.x.

Drechsler C (1960) Two new species of Conidiobolus found in plant detritus. American Journal of Botany 47: 368-377. https://doi.org/10.1002/j.1537-2197.1960.tb07138.x.

Drechsler C (1965) A robust Conidiobolus with zygospores containing granular parietal proto[1]plasm. Mycologia 57(6): 913-926. https://doi.org/10.2307/3756891.

Goffre D, Jensen AB, Lopez Lastra CC, Humber RA Folgarait PJ (2020). Conidiobolus lunulus, a new entomophthoralean species isolated from leafcutter ants. Mycologia (Online).

https://doi.org/10.1080/00275514.2020.1816387.

Gryganskyi AP, Humber RA, Smith ME, Miadlikovska J, Wu S, Voigt K, Walther G, Anishchenko IM, Vilgalys R (2012). Molecular phylogeny of the Entomophthoromycota. Molecular Phylogenetics and Evolution 65: 682-694. https://doi.org/10.1016/j.ympev.2012.07.026.

Gryganskyi AP, Humber RA, Smith ME, Hodge K, Huang B, Voigt K, Vilgalys R (2013). Phylogenetic lineages in Entomophthoromycota. Persoonia 30: 94-105. https://doi.org/10.3767/003158513X666330.

Guindon S, Gascuel O (2003). A simple, fast and accurate method to estimate large phylogenies by maximumlikelihood. Systematic Biology 52:696-704. https://doi.org/10.1080/10635150390235520.

Hall TA (1999). BioEdit: a user-friendly biological sequence alignment editor and analysis program for Windows 95/98/NT. Nucleic Acids Symposium Series 41:95-98.

Huang B, Humber RA, Hodge KT (2007). A new species of Conidiobolus from Great Smoky Mountains National Park. Mycotaxon 100:227-233.

Jensen AB, Gargas A, Eilenberg J, Rosendahl S (1998). Relationships of the insect-pathogenic order Entomophthorales (Zygomycota, Fungi) based on phylogenetic analyses of nucleus small subunit ribosomal DNA sequences (SSU rDNA). Fungal Genetics and Biology 24(3):325-334.

https://doi.org/10.1006/fgbi.1998.1063.

Page $12 / 16$ 
Keller S. 2007. Arthropod-pathogenic Entomophthorales from Switzerland. III. First additions. Sydowia 59:75113. https://doi.org/10.1002/yea.1500.

King DS (1976a). Systematics of Conidiobolus (Entomophthorales) using numerical taxonomy I. Taxonomic considerations. Canadian Journal of Botany 54:45-65. https://doi.org/10.1139/b76-008.

King DS (1976b). Systematics of Conidiobolus (Entomophthorales) using numerical taxonomy II. Taxonomic considerations. Canadian Journal of Botany 54:1285-1296. https://doi.org/10.1139/b76-141.

King DS (1977). Systematics of Conidiobolus (Entomophthorales) using numerical taxonomy III. Descriptions of recognized species. Canadian Journal of Botany 55:718-729. https://doi.org/10.1139/b77-086.

Lutzoni F, Kauff F, Cox CJ, McLaughlin D, Celio G, Dentinger B, Padamsee M, Hibbett DS, James TY, Baloch E, Grube M, Reeb V, Hofstetter V, Schoch C, Arnold AE, Miadlikowska J, Spatafora J, Johnson D, Hambleton S, Crockett M, Schoemaker R, Sun GH, Lücking R, Lumbsch HT, O’Donnell K, Binder M, Diederich P, Ertz D, Gueidan C, Hall B, Hansen K, Harris RC, Hosaka K, Lim YW, Liu Y, Matheny B, Nishida H, Pfister D, Rogers J, Rossman A, Schmitt I, Sipman H, Stone J, Sugiyama J, Yahr R, Vilgalys R (2004). Where are we in assembling the Fungal Tree of Life, classifying the fungi and understanding the evolution of their subcellular traits? American Journal of Botany 91(10):1446-1480.

Mendoza L, Vilela R, Voelz K, Ibrahim AS, Voigt K, Lee SC (2014). Human fungal pathogens of Mucorales and Entomophthorales. Cold Spring Harb Perspect Med 5(4):1-33. https://doi.org/10.1101/cshperspect.a019562.

Nie Y, Yu CZ, Liu XY, Huang B (2012). A new species of Conidiobolus (Ancylistaceae) from Anhui, China. Mycotaxon 120:427-435. https://doi.org/ 10.5248/120.427.

Nie Y, Tang XX, Liu XY, Huang B (2016). Conidiobolus stilbeus, a new species with mycelial strand and two types of primary conidiophores. Mycosphere 7(6):801-809. https://doi.org/10.5943/mycosphere/7/6/11.

Nie Y, Tang XX, Liu XY, Huang B (2017). A new species of Conidiobolus with chlamydospores from Dabie Mountains, eastern China. Mycosphere 8(7):809-816. https://doi.org/10.5943/mycosphere/8/7/1.

Nie Y, Qin L, Yu DS, Liu XY, Huang B (2018). Two new species of Conidiobolus occurring in Anhui, China. Mycological Progress 17(10):1203-1211. https://doi.org/10.1007/s11557-018-1436-z.

Nie Y, Wang L, Cai Y, Tao W, Zhang YJ, Huang B (2019). Mitochondrial genome of the entomophthoroid fungus Conidiobolus heterosporus provides insights into evolution of basal fungi. Applied Microbiology and Biotechnology 103(3):1379-1391. https://doi.org/10.1007/s00253-018-9549-5.

Nie Y, Yu DS, Wang CF, Liu XY, Huang B (2020a). A taxonomic revision of the genus Conidiobolus (Ancylistaceae, Entomophthorales): four clades including three new genera. Mycokeys 66: 55-81. https://doi.org/10.3897/mycokeys.66.46575.

Nie Y, Cai Y, Gao Y, Yu DS, Wang ZM, Liu XY, Huang B (2020b). Three new species of Conidiobolus sensu stricto from plant debris in eastern China. MycoKeys 73: 133-149. https://doi.org/10.3897/mycokeys.73.56905.

Rambaut A (2012). FigTree version 1.4.0. Available at http://tree.bio.ed.ac.uk/software/figtree/ 
Ronquist F, Huelsenbeck JP (2003). MRBAYES 3: Bayesian phylogenetic inference under mixed models. Bioinformatics 19:1572-1574. https://doi.org/10.1093/bioinformatics/btg180.

Spatafora JW, Chang Y, Benny GL, Lazarus K, Smith ME, Berbee ML, Bonito G, Corradi N, Grigoriev I, Gryganskyi A, James TY, O'Donnell K, Roberson RW, Taylor TN, Uehling J, Vilgalys R, White MM, Stajich JE (2016). A phylumlevel phylogenetic classification of zygomycete fungi based on genome-scale data. Mycologia 108(5): 10281046. https://doi.org/10.3852/16-042.

Srinivasan MC, Thirumalachar MJ (1962). Studies on species of Conidiobolus from India-II. Sydowia, Annales Mycologici 16: 60-66.

Srinivasan MC, Thirumalachar MJ (1968). Two new species of Conidiobolus from India. Journal of the Mitchell Society 84: 211-212.

Stamatakis A (2014). RAxML version 8: A tool for phylogenetic analysis and post-analysis of large phylogenies. Bioinformatics 30(9):1312-1313. https://doi.org/10.1093/bioinformatics/btu033.

Swofford DL (2002). PAUP*: Phylogenetic analysis using parsimony (*and other methods), Version 4.0b10. Sinauer Associates, Sunderland.

Tosi S, Caretta G, Humber RA. 2004. Conidiobolus antarcticus, a new species from continental Antarctica. Mycotaxon 90:343-347. https://doi.org/10.1111/j.1439-0507.2004.01029.x.

Vaidya G, Lohman DJ, Meier R (2011). SequenceMatrix: concatenation software for the fast assembly of multigene datasets with character set and codon information. Cladistics 27(2): 171-180. https://doi.org/10.1111/j.1096-0031.2010.00329.x.

Vilela R, Silva SMS, Correa FR, Dominguez E, Mendoza L (2010). Morphologic and phylogenetic characterization of Conidiobolus lamprauges recovered from infected sheep. J Clin Microbiol 48:427-432.

https://doi.org/10.1128/JCM.01589-09.

Vilgalys R, Hester M (1990). Rapid genetic identification and mapping of enzymatically amplified ribosomal DNA from several Cryptococcus species. Journal of Bacteriology 172:4238-4246.

https://doi.org/10.1128/jb.172.8.4238-4246.1990.

Vu D, Groenewald M, de Vries M, Gehrmann T, Stielow B, Eberhardt U, Al-Hatmi A, Groenewald JZ, Cardinali G, Houbraken J, Boekhout T, Crous PW, Robert V, Verkley GJM (2019). Large-scale generation and analysis of filamentous fungal DNA barcodes boosts coverage for kingdom fungi and reveals thresholds for fungal species and higher taxon delimitation. Studies in Mycology 92: 135-154. https://doi.org/10.1016/j.simyco.2018.05.001.

Waingankar VM, Singh SK, Srinivasan MC (2008). A new thermophilic species of Conidiobolus from India. Mycopathologia 165:173-177. https://doi.org/10.1007/s11046-007-9088-6.

Wang YL, Nie Y, Yu DS, Xie XY, Qin L, Yang Y, Huang B (2020). Genome-wide study of saprotrophy-related genes in the basal fungus Conidiobolus heterosporus. Applied Microbiology and Biotechnology 104(14):6261-6272. https://doi.org/10.1007/s00253-020-10698-6. 
Watanabe M, Lee K, Goto K, Kumagai S, Sugita-Konishi Y, Hara-Kudo Y (2010). Rapid and effective DNA extraction method with bead grinding for a large amount of fungal DNA. Journal of Food Protection 73(6):10771084. https://doi.org/10.4315/0362-028X-73.6.1077.

Waters SD, Callaghan AA (1989). Conidiobolus iuxtagenitus, a new species with discharge elongate repetitional conidia and conjugation tubes. Mycological Research 93:223-226. https://doi.org/10.1016/S0953-

7562(89)80121-2.

Zollera S, Scheideggera C, Sperisena C (1999). PCR primers for the amplification of mitochondrial small subunit ribosomal DNA of lichen-forming ascomycetes. The Lichenologist 31(5):511-516.

https://doi.org/10.1006/lich.1999.0220.

\section{Figures}

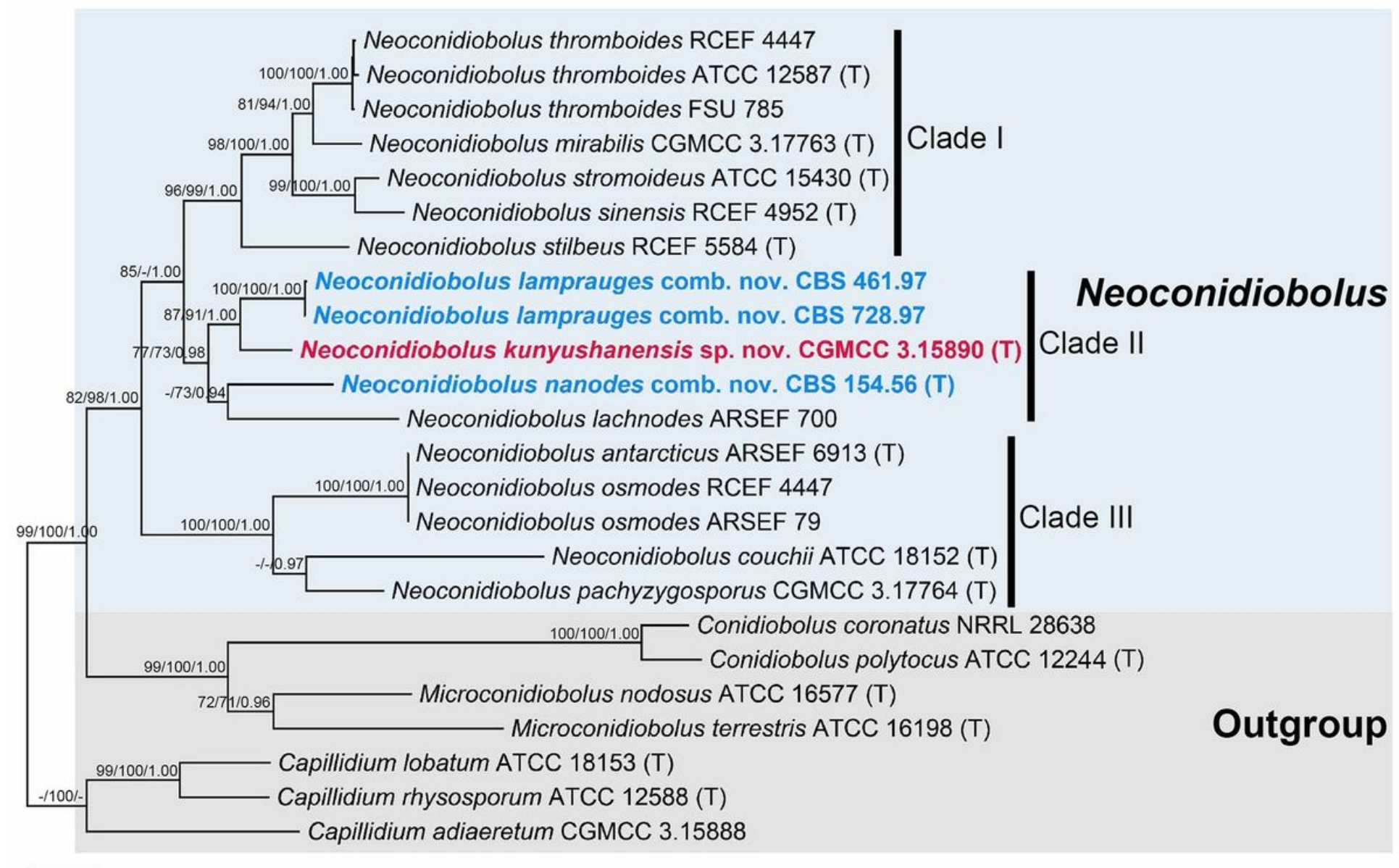

0.05

\section{Figure 1}

The phylogenetic tree of Neoconidiobolus constructed by Maximum Likelihood analyses of nucLSU, TEF1 and mtSSU sequences, with seven strains in Conidiobolus s.l. as outgroups. N. kunyushanensis sp. nov. is shown in red. N. lampauges comb. nov. and N. nanodes comb. nov. are shown in blue. Maximum Parsimony bootstrap values ( $\geqq 70 \%)$ / Maximum Likelihood bootstrap values ( $\geqq 70 \%)$ / Bayesian Inference posterior probabilities 
$(\geqq 0.95)$ of each clade are indicated along branches. Scale bar indicates substitutions per site. "T" indicates the ex-type cultures.

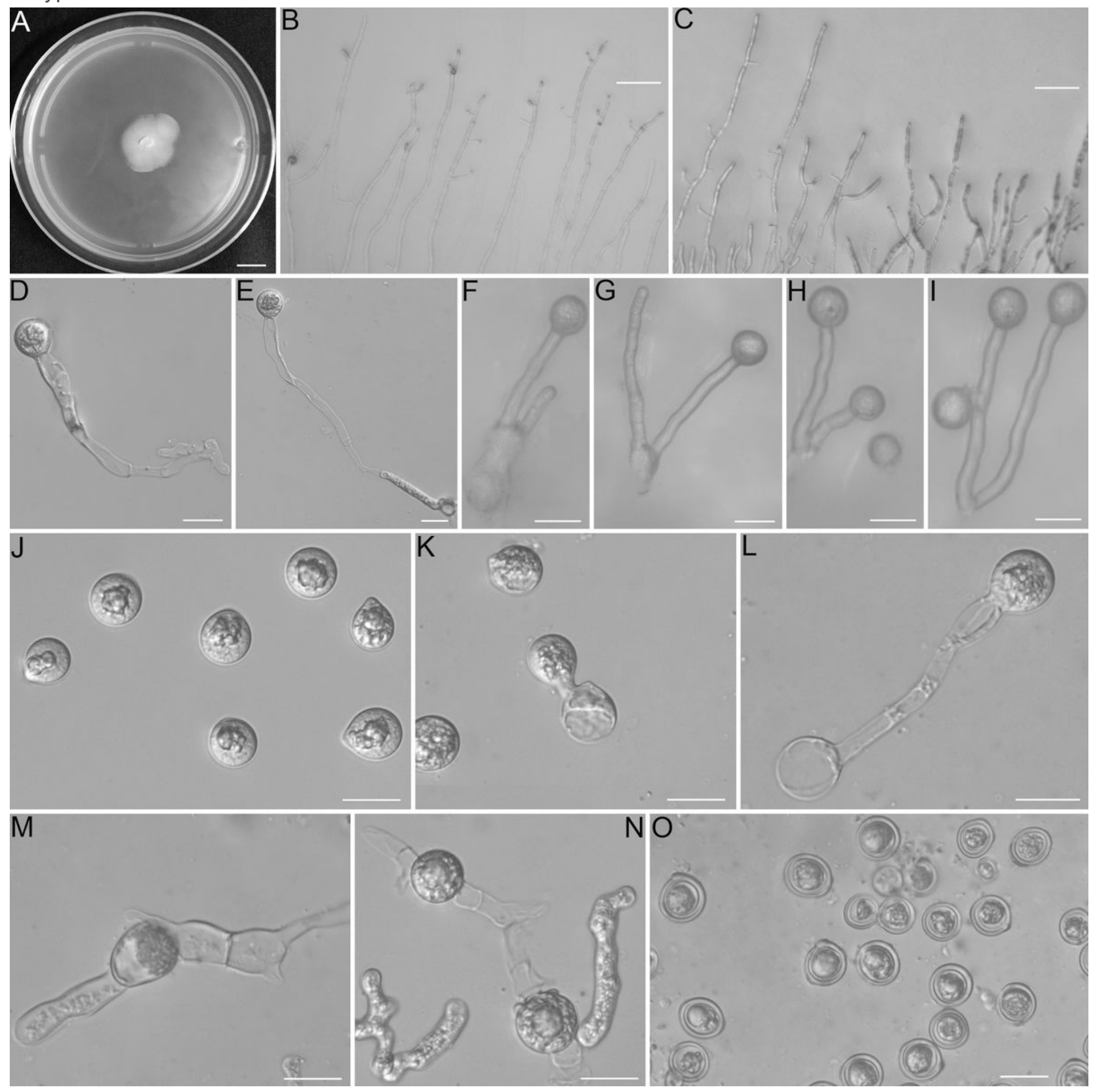

Figure 2

A-O. Neoconidiobolus kunyushanensis CGMCC 3.15890. A. Colony on PDA after $3 \mathrm{~d}$ at $21^{\circ} \mathrm{C} ; \mathrm{B}, \mathrm{C}$ Mycelia branched at the colony edge; D, E. Single primary conidiophores with widening upward near the tip and bearing a primary conidium; F - I. Two primary conidiophores without widening upward near the tip arising from hyphal body at the same point and bearing two primary conidia; J. Primary conidia; K, L. Producing secondary conidia; M, N. Zygospores formed between segments of separate hyphae; O. Zygospores. - Scale bars: A = 10 mm; B - C $=100 \mu \mathrm{m} ; \mathrm{D}-\mathrm{O}=20 \mu \mathrm{m}$. 